\title{
Oculocutaneous albinism type 4
}

INSERM

\section{Source}

INSERM. (1999). Orphanet: an online rare disease and orphan drug data base.

Oculocutaneous albinism type 4. ORPHA:79435

Oculocutaneous albinism type 4 (OCA4) is a type of OCA (see this term) characterized by varying degrees of skin and hair hypopigmentation, numerous ocular changes and misrouting of the optic nerves at the chiasm. 